\title{
EESTI ETNOGRAAFIA JA EESTI RAHVUSLUS
}

\author{
INDREK JÄÄTS, MARLEEN METSLAID
}

$\mathrm{E}$ tnograafia (etnoloogia) kui kultuuri, ühiskonda ja rahvast (rahvaid) uuriv teadusharu on alati olnud seotud ideoloogia ja poliitikaga (vt Bendix 1999; Klein 2006). Etnograafia tekkis ja arenes XIX sajandil ning XX sajandi algul konkreetsetes riiklikes oludes ning seetõttu on erinevates maades mõneti erinenud nii distsipliini nimetused, meetodid kui ka uurimisobjektid. Eestis oli teadusharu nimetuseks kuni 1990. aastateni etnograafia ning selle peamiseks uurimisalaks traditsioonilise talurahvakultuuri materiaalne külg. ${ }^{1}$ Pärast taasiseseisvumist sulatati Eesti etnograafia kiiresti ühte Euroopa etnoloogiaga ${ }^{2}$ ning vastavalt muutus ka nimetus.

Rahvuslus on ajaloos suhteliselt hiline, XVIII sajandi lõpul Lääne-Euroopas ja tema Ameerika kolooniates tekkinud nähtus, mis on orgaaniliselt seotud moderniseerumisega (vt Gellner 1994-1995). Laiemas tähenduses on rahvuslus modernse maailma kultuuriline raamistik, kognitiivne süsteem, mis kujundab ja varustab tähendusega kogu sotsiaalset reaalsust ning on ühtlasi prismaks, läbi mille seda reaalsust nähakse (Greenfeld 2001: 254; vt ka Özkırımlı 2000: 4).

Rahvuslus sünnitab rahvusi. Rahvastikust saab kodanikkond ehk rahvus. (Paljudes maades, eriti Lääne-Euroopas, on need kattuvad mõisted.) Sõna rahvas, millega varem tähistati sotsiaalseid alamkihte, omandab „rahvusluse ajastul" positiivse tähenduse. Rahvuseks saanud rahvas on sõltumatu ja ise ennast valitsev. Modernne (rahvus)riik saab oma legitiimsuse rahvuselt, väljendab ja viib ellu rahva huve, vähemalt teoreetiliselt. (vt Greenfeld 2001: 252-254)

Konkreetsetes oludes ellu rakendatuna võtab rahvuslus kui kognitiivne süsteem spetsiifilise vormi. Sellest saab rahvuslus kitsamas tähenduses, konkreetne rahvuslus, näiteks eesti rahvuslus. ${ }^{3}$ Viimane tekkis Euroopas levivate ideede mõjul XIX sajandi keskpaigas, esialgu väheste haritlaste peas, kuid hakkas siis tasapisi levima, kuna väljendas eestikeelse rahvastiku - rahvusluse retoorikas e esti rahva - huve. Rahvuslikult meelestatud haritlaste juhtimisel hakati järk-järgult vormima eesti rahvust ning eesti rahva kultuur oli selle ülesehitustöö käigus loomulikult väga oluline. Etnograafia oli rahvusluse kaasleja. Haritud inimesed ei olnud varemalt talupoegade kultuuri vastu erilist huvi tundnud. Rahvakultuur sai tähtsaks uurimisobjektiks alles rahvusluse raames.

${ }^{1}$ Käesolevas artiklis kasutatakse sõna etnograafia just selles tähenduses. Eesti keeles on etnograafiat nimetatud ka rahvateaduseks, eriti sõdadevahelisel perioodil. Tegemist on kreeka keelest pärineva termini (ethnos 'rahvas', grapho 'kirjutan') tõlkevastega. Eeskujudeks olid soomekeelne kansatiede ja saksakeelne Volkskunde.

${ }^{2}$ Euroopa etnoloogia all mõistame tänapäeval etnoloogilist ja folkloristlikku uurimistööd Euroopas, mille põhieesmärgiks on igapäevaelu analüüsimine.

${ }^{3}$ Rahvuslusest ja rahvusest pikemalt vt Jääts 2005, 1. peatükk ja seal viidatud kirjandus. 
Artiklis vaatleme Eesti etnograafia tekkimist ja ajalugu erinevate poliitiliste režiimide ajal. Keskseks teljeks on distsipliini seos eesti rahvuslusega. Pikemalt keskendume kahele perioodile: sõdadevahelisele ajale, kui Eesti oli iseseisev rahvusriik ning etnograafia kui üks rahvusteadusi aitas kaasa rahvusliku identiteedi ja ühtsustunde tugevdamisele; ning nõukogude perioodile, mil Eesti etnograafia oli allutatud nõukogude etnograafiale ning pidi järgima selle marksistlik-leninistlikku teooriat, kuid säilitas siiski seose eesti rahvuslusega ja toetas eesti identiteeti. Viimaste kümnendite Eesti etnoloogia ajaloo mõtestamiseks on ajalooline distants meie meelest veel liiga napp ning saame toimunud arengutest visandada vaid esialgse ja üpris subjektiivse pildi.

\section{Eesti etnograafia kujunemine}

Kuni XIX sajandi keskpaigani olid eestlased omakeelse eliidita talupojarahvas, kes ise endast ei kirjutanud, kuid pakkus huvi teistele, eeskätt baltisaksa ja vene haritlastele. Baltisakslastest valgustajad hakkasid juba XVIII sajandi lõpul uurima eesti (ja läti) talupoegade eluolu, eesmärgiga rahvast harida ja tema elujärge parandada. Romantismi vaimust kantuna ja Johann Gottfried Herderi ideedest lähtudes tunti eesti rahvakultuuri, eeskätt rahvalaulude vastu ka puhttunnetuslikku huvi. Neis nähti väärtust omaette. Rahvuslus kui sotsiaalse maailma tajumise viis oli tasahilju levinud Venemaa Balti provintsidesse. Sellest mõjutatud haritlased panid justkui uued prillid ette ja nägid, et valdavalt talupoegadest koosnev rahvastik jaguneb rahvasteks etnilises tähenduses ning igaühel neist on oma kordumatu keel ja kultuur, mis väärib tähelepanu ja lähemat uurimist. Eesti rahvuslust veel ei olnud, aga see sündis üsna pea.

Kui baltisaksa ja vene uurijaile olid eestlased lihtsalt üheks etnograafiliseks objektiks, siis soome haritlaste jaoks olid nad keelesugulased, hõimurahvas. Soome rahvateadus (sm kansatiede) sündis mõnevõrra varem kui Eesti etnograafia ning avaldas viimasele olulist mõju. (Leete jt 2008: 16)

XIX sajandi teisel poolel kerkisid esile juba eestlaste endi seast võrsunud haritlased, kes hakkasid pöörama tähelepanu eeskätt talurahva vaimsele kultuurile: rahvalauludele (regilaulule), muistenditele ja muinasjuttudele. Neid hakati koguma, uurima ja publitseerima. See sündis varasemast erinevas kontekstis, oli osa rahvuslikust liikumisest. Eestlased, nagu öeldud, olid nn ajaloota rahvas ning haritlastel, kes asusid ehitama modernset eesti rahvust, polnud materjaliks võtta eriti midagi peale traditsioonilise talurahvakultuuri. Rahvaluule kõrval hakati huvituma ka selle materiaalsest küljest. Rahvusluse raames omistati rahvakultuurile uus, positiivne tähendus. Selle valitud elemente hakati väärtustama kui rajatava rahvuskultuuri lähtekohta ja vundamenti (vt Kannike 1994: 9).

Nõndaviisi sai traditsiooniline talurahvakultuur rahvusliku identiteedi seisukohalt oluliseks. Aastakümneid on see olnud folkloristide ja etnograafide peamine uurimisobjekt ning teinud algul väga tihedalt põimunud folkloristikast ja etnograafiast rahvusteadused.

Esimesed eesti rahvateadlased huvitusid kõigest, mis oli võimalikult vana ja arhailine, sest selles nähti avalduvat „muistset hiilgust” (Kannike 1994: 11). 
XIX sajandi lõpul ja XX sajandi algul moderniseerus Eesti ala küllalt kiiresti, rahva elulaad muutus ja traditsiooniline rahvakultuur kippus kaduma: vanad laulud vajusid unustusehõlma, juba loobuti paljudes kohtades kandmast rõivaid, millele just tollal omistati rahvarõiva staatus. Rahvuslikult meelestatud haritlased mõistsid, et kui tahetakse sellest kõigest midagi teaduse ja tulevaste põlvede tarvis päästa, tuleb tegutseda kiiresti.

Idee Eesti muuseumist tekkis rahvuslikult mõtlevatel haritlastel juba XIX sajandi teisel poolel. Eesti Rahva Muuseumi (ERM, asutatud aastal 1909 Tartus) loomise vahetuks ajendiks oli rahvusliku liikumise ja rahvaluulekogumise suurkuju Jakob Hurda (1839-1907) surm (Leete jt 2008: 16-17). Muuseumi juhatuse esimeheks valiti Oskar Kallas (1868-1946), esimene eestlasest folkloristikadoktor (1901) ning vaimse ja materiaalse rahvapärandi kogumise eestvedaja. Muuseum, mis oli loodud küll Hurda mälestuseks ja tema rahvaluulekogude säilitamiseks, keskendus esialgu vana talupojakultuuri materiaalse poole, eeskätt rahvakunsti kogumisele ja populariseerimisele. ${ }^{4}$ Vaatamata kindlate ruumide puudumisele mängis muuseum oma esimesel tegutsemiskümnendil aktiivset rolli eesti rahvuslikus liikumises. Muuseumi egiidi all ja kunstnik Kristjan Raua (1865-1943) juhtimisel toimus rida kogumisretki, mis suurendasid ühelt poolt muuseumi kogusid, teisalt aga kasvatasid eestlaste rahvuslikku eneseteadlikkust ja õpetasid väärtustama oma talupoeglikku kultuuripärandit, mida tollases keelepruugis tähistati austava nimetusega vanavara. ${ }^{5}$ Aastate jooksul kujunesid suured ainelise vanavara kogud ning Esimese maailmasõja aastateks tunnetati juba nende süstematiseerimise ja uurimise vajadust. See omakorda viis Eestis etnograafia kujunemiseni iseseisvaks teadusdistsipliiniks.

Eesti arengud polnud erandlikud. ${ }^{6} \mathrm{Ka}$ teiste Põhja- ja Ida-Euroopa väikeste rahvuste juures sündis etnograafia „koguva teaduse” ja „rahvusliku päästeaktsioonina”, mille eesmärgiks oli rahvuse konsolideerimine „oma” kultuuri uurimise kaudu (vt Löfgren 1990). (Rahva)kultuur „rahvuslikustati” (vrd Löfgren 1989), eraldati kaasajast ja paigutati ebamäärasesse minevikku, mille viimased reliktid olid kaugemates maapiirkondades veel uurijate jaoks leitavad. Päästmisdiskursus püsis rahvakultuurist kui uurimisobjektist rääkides elujõulisena XX sajandi lõpuni.

Tsaari-Venemaal, mille rüppe eestlaste asuala tollal kuulus, oli etnograafia tekkinud juba XVIII sajandi lõpul. Nii Kreutzwaldil kui ka Hurdal olid sidemed Vene Geograafia Seltsiga (asutatud aastal 1845) ning nende teadmusloomet võib soovi korral pidada osaks Vene etnograafiast. Keiserlikus Tartu ülikoolis õpetati samuti etnograafiat, seotuna geograafia ja statistikaga. Ühes rahvusliku eneseteadvuse kasvuga arvasid eesti rahvateadlased end aga välja vene ja baltisaksa teadustraditsioonidest. Kui Ilmari Manninen 1924. aastal Eesti etnograafia defineeris, siis ütles ta muuhulgas: „Aineline rahvateadus, etnograafia, on Eestis sõna tõsises mõttes uus teadus” (1924: 527).

${ }^{4}$ Hurda kogud asusid kuni 1927. aastani Helsingis. Siis loodi ERM-i juurde Eesti Rahvaluule Arhiiv ja kogud toodi kodumaale.

${ }^{5}$ Vanavara mõistet kasutas Hurt juba 1870. aastatel (Valk 2004) ning see termin on püsinud eesti kultuuriloolises sõnavaras tänaseni.

${ }^{6}$ Paralleelide kohta näiteks Rootsis vt Klein 2006: 58-59. 


\section{Eesti etnograafia etableerumine 1920. ja 1930. aastail}

Iga rahvusluse, õigemini rahvuslaste ülimaks püüdeks on luua oma rahvusriik - rahvuse loomulik olemisvorm. Eesti Vabariik loodi aastail 1918-1920, ajal, mil rahvuslus oli tõusuteel kõikjal Euroopas ning isegi suur osa kommuniste mõtles rahvuslikes kategooriates. Noor Eesti rahvusriik pidi üles ehitama oma ideaalidele ning vajadustele vastava haridus- ja teadussüsteemi. Etnograafia ühes teiste rahvusteadustega (folkloristika, ajalugu, arheoloogia, kirjandusteadus, keeleteadus, kunstiajalugu) sai uutes oludes võimaluse muutuda iseseisvaks akadeemiliseks distsipliiniks ning töötada kaasa rahvusliku identiteedi tugevdamisel ja riikliku identiteedi loomisel. „Rahvusliste ainete”, ${ }^{7}$ nagu neid 1920. aastatel nimetati, ülesandena nähti „eesti rahva omapära valgustamist ja kinnitamist" (Manninen 1924: 527).

Etnograafide põhiliseks institutsionaalseks baasiks kujunes ERM. Muuseumi ja 1919. aasta detsembris eestikeelse ja -meelse õppeasutusena taasalustanud Tartu Ülikooli (TÜ) vahel tekkis tihe koostöö. TÜ etnograafia õppejõuks kutsuti noor soome teadlane Ilmari Manninen (1894-1935). Ühtlasi sai temast ka ERM-i direktor (1922). Eeskuju võeti Soomest ja Rootsist: akadeemilise etnograafia ja muuseumikogude vahel pidi olema tihe side (vt Niiranen 1992; Klein 2006). Etnograafilistes kogudes nähti suurt rahvuslikku väärtust, samal ajal ootasid need alles läbiuurimist. Manninen pani aluse ERM-i etnograafiliste kogude teaduslikule süstematiseerimisele ja täiendamisele, avaldas esimese erialase sõnastiku („Etnograafiline sõnastik”, 1925) ning alustas muuseumi aastaraamatu väljaandmist (1925), luues seega erialaste lühiuurimuste avaldamise areeni. Mitmed Mannineni tudengid asusid ERM-i tööle: Ferdinand Linnus (1895-1942, nime eestistamiseni Leinbock), Gustav Ränk (1902-1998), Helmi Kurrik (1883-1960). Mannineni kodumaale naasmise järel (1928) jäi TÜ etnograafia õppetool kuni 1930. aastate lõpuni vakantseks ning see aitas kinnistada ERM-i juhtivat rolli Eesti etnograafias. Muuseumidirektori kohused võttis Manninenilt üle tema õpilane F. Linnus, kes oli sellel ametikohal kuni 1941. aastani.

Defineerides etnograafia teadusena, mis tegeleb vaid materiaalse talurahvakultuuri uurimisega, kinnistas Manninen teadusala seotuse etnograafiliste muuseumikogudega. TÜ etnograafia dotsendina avaldas ta programmi, milles nimetas eriala eesmärgiks tervikliku ülevaate loomise eesti materiaalsest talupojakultuurist. Selleks tuli esmalt luua kultuurifenomenide tüpoloogia ja kindlaks määrata nende geograafiline levik. Lisaks pidi uurimistöö käigus välja selgitatama seosed eestlaste ja naaberrahvaste materiaalse kultuuri vahel. (Manninen 1924) Nende tegevussuuniste loomisel lähtus Manninen ühelt poolt kohalikust kultuuriloolisest taustast ning teisalt lähiriikides toimuvatest distsiplinaarsetest arengutest.

Manninen juurutas ajaloolis-geograafilise meetodi, mida tollal järgiti ka mujal Kesk- ja Põhja-Euroopas. Sellega seoses kujunes oluliseks meetodiks etnograafiliste nähtuste kaardistamine, peamiselt muuseumikogude läbitöötamiseks, aga ka uurimistööks. Kartograafilise meetodi eduka rakendamisega

${ }^{7}$ Ants Viirese arvates on see sõnaühend moodustatud soome eeskujul (kansalliset tieteet) (Viires 2000: 5). 
olid Eesti etnograafid tollal Euroopas esirinnas. Manninen rõhutas vajadust uurida etnograafiliste esemete kultuuriloolist konteksti, nende valmimis- ja kasutamiskeskkonda. (Talve 1992; vrd Rogan 2014)

Tollaste Eesti etnograafide peamisteks uurimisteemadeks olid rahvarõivad, rahvakunst, ehitised, kalastus, mesindus ning toit. 1930. aastatel jõudsid nad tähelepanuväärsete teoste väljaandmiseni. ${ }^{8}$ Teadmusloomes ei tuginetud ainult muuseumikogudele, tihedalt teadustegevusse integreeritud välitööd olid isegi tähtsamad. „Väljale” mindi aasta-aastalt tagasi, et oma teadmisi täiendada. Samuti saadeti välitöödele tudengeid ning kasutati kohalikke kaastöölisi, kellele saadeti vastamiseks etnograafide koostatud temaatilisi küsitluskavu. ERM-i korrespondentide võrk loodi ametlikult 1931. aastal. See aitas rahvast kaasata ja muuseumiga siduda.

Analüüsides lähemalt tollaste etnograafide teaduslikke praktikaid nende erinevates väljendusvormides (välitööpäevik, esmane etnograafiline kirjeldus, teadustöö, populaarteaduslik artikkel, muuseumi näitus), ilmneb uurijate mitmetine lähenemine rahvakultuurile. Kuigi Mannineni programm oli piiritletud kitsalt minevikulise materiaalse talupojakultuuriga, siis isiklikus teadmusloomes nägid etnograafid rahvakultuuri laiemalt, nii temaatilises kui ka ajaliste raamide mõttes. (Vt lähemalt Metslaid 2016)

Eesti etnograafid tegelesid uurimisteemadega, mis olid ühelt poolt rahvusvahelised ja teisalt rahvuslikult olulised. Kirjavahetuste, konverentside ja saksakeelsete publikatsioonide kaudu olid nad dialoogis kolleegidega lähematest ja kaugematest riikidest, kus tegeleti sarnase teadustööga. Nõnda panustati ühtlasi nii üleeuroopalisse teadmusringlusse kui ka modernse rahvuse loomisse (vrd Rihtman-Auguštin 2004; Klein 2006; Nic Craith 2008).

Iseloomulikult on Eesti etnograafias algusest peale uuritud ka teisi soomeugri rahvaid. See on sidunud Eesti etnograafiat tema Soome vastega. Teadmine, et eesti ja soome keel kuuluvad soome-ugri keeleperre, mängis eesti ja soome rahvuslikus identiteedis olulist rolli juba alates XIX sajandist ning keelesugulust laiendati sageli ka kultuuri- ja isegi veresuguluseks. Soomeugrilastest räägiti kui hõimurahvastest. Sõdadevahelisel perioodil ei pääsenud Eesti etnograafid poliitilistel põhjustel Nõukogude Liidus elavate idapoolsete soomeugrilaste juurde ning erinevalt Soome kolleegidest polnud neil ka suuri andmekogusid varasemast perioodist. Võimaluste piires teiste soome-ugri rahvastega siiski tegeleti. Näiteks Ferdinand Linnus tegi Ilmari Mannineni suunamisel aastaid välitöid Läti liivlaste juures. Käidi ka nn Eesti-Ingeris ja Soome Karjalas. Ambitsioonid olid aga märksa suuremad.

Rahvuslus oli sõdadevahelises Eestis (ja Euroopas laiemalt) peaaegu ainuvaldav ja sedavõrd enesestmõistetav ning loomulik, et seda õieti ei teadvustatudki. Eesti etnograafide põhilist tegevusareeni ERM-i mõtestati selle asutamisest alates rahvusmuuseumina. Rahvusliku institutsioonina mõjutas muu-

\footnotetext{
${ }^{8}$ Manninen avaldas kolmeosalisena kavandatud koguteose „Die Sachkultur Estlands” kaks esimest köidet $(1931,1933)$. Linnuselt (resp. Leinbockilt) ilmus ülevaade „Die materielle Kultur der Esten” (1932). Ränk avaldas populaarteadusliku ülevaate „Vana-Eesti rahvakultuur" (1935). Lisaks ilmusid tollaste etnograafide sulest järgmised monograafiad: Mannineni „Eesti rahvariiete ajalugu” (1927), Ränga „Peipsi kalastusest” (1934) ning „Saaremaa taluehitised I” (1939) ja Linnuse „Eesti vanem mesindus. I Metsamesindus” (1939). Viimased kaks põhinesid esimestel Eestis kaitstud etnograafiaalastel doktoritöödel.
} 
seum seal töötanud uurijate teadmusloomet peamiselt näituste valdkonnas. Seni ajutistes ruumides asunud muuseum sai 1922. aastal enda kasutusse Raadi mõisahoone Tartu põhjapiiril. Eesti kultuurilugu ning soome-ugri kultuure tutvustavad näitused (avati vastavalt aastatel 1927 ja 1928) kujunesid rahvuslikkuse manifestatsiooniks. Eesti rahvakultuuri esitleti muuseumis eraldiseisva, unikaalse ja staatilisena ning mõnevõrra idealiseeritult (vt lähemalt Metslaid 2016: 62).

Etnograafide ja ERM-i seosed riigivõimuga tihenesid pärast 1934. aasta autoritaarset pööret. Kultuuri ja ideoloogia vallas seadis uus võim esiplaanile ühtse rahvusriigi tugevdamise. Muuseum läks rahvusliku kultuuri propageerimise aktsioonidega kaasa. Eelkõige osaleti rahvarõivaste populariseerimises: ilmus Helmi Kurriku käsiraamat „Eesti rahvarõivad” (1938). ERM-i tegevusprintsiibid ja sihid kattusid tegelikult niigi suuresti rahvusliku kultuuripropaganda eesmärkidega, probleeme tekitas liigne riigipoolne surve. (Vt pikemalt Nõmmela 2010.) Tollaste etnograafide teadmusloome tundub siiski olevat ajendatud pigem üldisemast rahvuslikust idealismist kui mingist kindlapiirilisest ideoloogilis-poliitilisest tellimusest (Metslaid 2016: 34-35).

1930. aastatel räägiti ajakirjanduses korduvalt rahvusteadustest. Etnograafia nimel võttis kõige elavamalt sõna Gustav Ränk. Defineerides rahvusteadusi distsipliinidena, mis „meie maas ja rahvas nii sügavalt juurduvad”, pidas ta nendel aladel tehtavat uurimistööd mitte ainult eestlaste eesõiguseks, vaid ka „suurimaks kohustuseks” (Ränk 1935: 178). Ränk sidus rahvusteaduste, konkreetsemalt etnograafia olemasolu ning akadeemilise taseme Eesti riigi ja rahva iseseisvusega. Rahvusteaduste puudumine või viletsus tähendaks eestlaste kultuurilist allakäiku. Ränk kirjutas: „Terviklik maailm ei salli tühikuid, ka teaduse maailm mitte; kui meie oma etnograafilise tegevusega ei suuda oma kohta ise täita meid ümbritsevate rahvaste peres, siis hakkavad selle vastu huvi tundma teised" (Ränk 1937: 122). ${ }^{9}$

Eesti etnograafia etableerumist täieõigusliku akadeemilise distsipliinina sümboliseerib Gustav Ränga asumine Tartu Ülikooli etnograafiaprofessori kohale aastal 1939.

\section{Sõja-aastad ja Eesti etnograafid paguluses}

Teine maailmasõda tähendas Eestile vahelduvaid okupatsioone. Segased ja ohtlikud ajad puudutasid ka etnograafe. 1941. aastal arreteeriti ERM-i direktor Ferdinand Linnus, kes suri järgmisel aastal Venemaal vangilaagris. Etnograafia professuur kaotati esimesel nõukogude aastal. Saksa okupatsiooni ajal töötas Ränk erakorralise professorina. Varem sihtasutusena tegutsenud ERM riigistati 1940. aasta sügisel ning jaotati kaheks, etnograafiamuuseumiks ja kirjandusmuuseumiks (viimase all olid ka rahvaluulekogud). Raadi mõisahoone hävis 1944. aastal, kuid õnneks oli jõutud evakueerida enamik seal hoitavast kultuuripärandist.

${ }^{9}$ Vrd 1930. aastate Rootsi etnoloogide vastuseisu võimalusele, et (natsionaalsotsialistlikud) Saksa uurijad tulevad uurima rootsi rahvakultuuri (Garberding 2011: 295). 
Sõja lõpuks oli suurem osa juhtivatest etnograafidest põgenenud läände: Gustav Ränk ja Eerik Laid (1904-1961) ning Ränga õpilased Helmut Hagar (1914-1991) ja Ilmar Talve (1919-2007) jõudsid Rootsi, Helmi Kurrik aga Saksamaa kaudu USA-sse. Uuel asukohamaal hakkasid nad kandma kahetist rolli, olles ühtlasi pagulased ja teadlased. Kui suudeti uurimistegevust jätkata, võeti sageli ette laiem perspektiiv, mõeldi rahvusvahelisele lugejaskonnale ning hakati tegelema ka asukohamaa teemadega (vt Viires 1998). Rängast sai hiljem Stockholmi ülikooli etnoloogia dotsent, Talvest Turu ülikooli etnoloogiaprofessor. Side Eesti teemadega üldjuhul säilis, nagu ka rahvuslik hoiak nende käsitlemisel. Etnograafiast kui rahvusliku identiteedi arendamise mehhanismist kirjutas Ränk ka ingliskeelsetele lugejatele (Ränk 1978: 323).

1950. aastate lõpust alates tekkisid mõnelgi pagulasetnograafil kontaktid ka oma kolleegidega Nõukogude Eestis.

\section{Etnograafia Nõukogude Eestis (1944-1991)}

Nõukogude periood Eesti ajaloos polnud ühetaoline. Muutused poliitikas ja ühiskonnas mõjutasid ka etnograafiat. Kui esimestel sõjajärgsetel aastatel jäeti Eesti ühiskonnale justkui väike hingetõmbeaeg, siis 1940. aastate lõpul algas poliitiliste repressioonide laine (haritlaste süüdistamine kodanlikus natsionalismis, küüditamine Siberisse ${ }^{10}$ põllumajanduse sundkollektiviseerimine). Hammasrataste vahele sattus ka etnograafe. Näiteks vabastati 1950. aasta märtsis toimunud EK(b)P KK VIII pleenumi järel ametist ERM-i tollane direktor Ida Kaldmaa. Pärast Stalini surma 1953. aasta märtsis repressioonid raugesid. Hruštšovi ja Brežnevi valitsusajal sai segipaisatud Eesti kodanikuühiskond taas konsolideeruda ning eksisteerida paralleelselt n-ö ametliku ühiskonnaga, põimudes sellega keerukalt. Nõukogude ideoloogia pealesurumine jätkus, ent senistest vähem jõhkrate meetoditega. Okupatsiooniaeg kujunes pikaks, eestlased olid sunnitud sellega kohanema. Samal ajal suur osa eestlasi umbusaldas nõukogude võimu ega jaganud selle ideaale ning püüdlusi. Ruum vaimseks iseolemiseks ja oma meelsuse ettevaatlikuks väljendamiseks leiti kultuurivallas. Paljud loovharitlased otsisid ja leidsid ikka ja jälle võimalusi tsensuurist mööda hiilida, et smugeldada rahvani nõukogude võimu omast lahknev sõnum. Mingil määral toimis selline praktika ka teaduses, eeskätt eesti identiteediga seotud teadusaladel. Humanitaarteadlaste seas leidus muidugi ka karjeriste, kes tegid režiimiga koostööd, kuid paljuski tegelesid nende distsipliinidega inimesed, kes väärtustasid rahvuslikke juuri, traditsioone ja identiteeti. Ka kommunistliku partei liige võis olla eestimeelne inimene ning võimalusel vastavalt tegutseda.

Rahvuslus kui sotsiaalse reaalsuse tajumise viis ei kadunud kuhugi. Kommunistlik õpetus nägi küll ette rahvuste kadumist, kuid see pidi juhtuma alles kaugemas tulevikus. Kaasajal olid rahvused reaalsus, mida nõukogude võim tunnustas. Võib isegi öelda, et nõukogude riik edendas etnilist partikularismi (Slezkine 1994). Nõukogude rahvaste rahvuskultuure toetati. Maha

${ }^{10}$ Küüditamise tulemusena jäi laokile hulk talurahva vara, mille vastu tundsid muuseas huvi ka etnograafid. 
suruti vaid nõukogudevaenulikku, nn kodanlikku natsionalismi. Aga piirid olid hägusad, eriti pärast Stalini surma.

Sõja järel tuli Eesti etnograafia allutada nõukogude ideoloogiale ning teha Nõukogude etnograafia osaks. 1940. aastateks oli Nõukogude etnograafiast kujundatud kindlalt kontrollitud tsentraliseeritud süsteem, mis tipnes NSVL Teaduste Akadeemia Etnograafia Instituudiga Moskvas. Rahvaid ja nende kultuure, eeskätt materiaalset kultuuri uurivat teadust nimetati Nõukogude Liidus etnograafiaks. See asjaolu aitas kinnistada distsipliini nimetust eesti keeles. Nõukogude Liidus käsitleti etnograafiat ajalooteaduse ühe haruna, selle teoreetiliseks aluseks oli ajalooline materialism. Lähtuti Lewis Henry Morgani ja Friedrich Engelsi evolutsionistlikest ideedest, mille kohaselt inimühiskonna arengu põhjustab materiaalsete hüvede tootmises toimuv progress. Lisaks teoreetilisele suunale oli Nõukogude etnograafial ka rakenduslik külg: etnograafia pidi kaasa aitama ühiskonna sotsialistlikule ümberkorraldamisele.

1944. aasta sügisel valitses Eesti etnograafias suur kaadrinappus. Pea kõik väljapaistvamad etnograafid olid uue okupatsiooni eest läände pagenud, Ferdinand Linnus repressioonide tõttu hukkunud. Sõja järel avatud nõukogulikus Tartu ülikoolis etnograafia professuuri ei taastatud. Uute etnograafide ettevalmistamise võttis oma hoole alla arheoloogiaprofessor Harri Moora (1900-1968). Peale arheoloogiakateedri likvideerimist 1950. aastal jätkus etnograafide ettevalmistamine NSV Liidu ajaloo kateedri juures. Tartu ülikoolis õpetasid etnograafiat teadlased, kes põhikohaga töötasid mujal, peamiselt ERM-is. Alaline etnograafia õppejõu koht loodi alles aastal $1970 .{ }^{11}$ (Leete jt 2008: 22)

Pärast sõda oli ERM ${ }^{12}$ endiselt sisuliselt ainus etnograafiaga tegelev teadusasutus Eesti NSV-s. Selle töötajaskond kasvas varasemaga võrreldes, ent samal ajal allutati muuseumi tegevus ideoloogilisele kontrollile. Sõjas hävinud Raadi mõisa peahoone asemele anti endine kohtuhoone, kus ruumi nappis algusest peale ning võimalus näitusi teha oli üsna piiratud. (Konksi 2009: 275)

1952. aastal moodustas Moora Tallinnas Teaduste Akadeemia Ajaloo Instituudi arheoloogiasektori juurde väikese etnograafide töörühma. Sellest kujunes Nõukogude Eesti etnograafia tippkeskus. Uurimisrühma juhiks oli pikka aega Ränga õpilane Ants Viires (1918-2015). Etnograafilisi esemekogusid sektori juurde ei loodud.

Ka ERM allus aastast 1946 Eesti NSV Teaduste Akadeemiale. 1963. aasta suvel viidi muuseum üle Eesti NSV kultuuriministeeriumi alluvusse. Teadustööle see hästi ei mõjunud, sest palgad olid muuseumis suhteliselt väikesed ja vähesed teaduskraadiga spetsialistid eelistasid töötada Teaduste Akadeemias (Konksi 2009: 275).

Üheks esimeseks sammuks Eesti etnograafia juhtimisel ühtsesse nõukogude sängi oli Nõukogude Liidu tollase „peaetnograafi”, NSVL TA Etno-

\footnotetext{
${ }^{11}$ Pikki aastaid töötas sellel kohal Arved Luts (1929-2005).

${ }^{12}$ Muuseumi nimi muutus nõukogude ajal korduvalt. Lihtsuse mõttes piirdume artiklis nimetusega Eesti Rahva Muuseum (ERM). Aastail 1952-1988 nimetati ERM-i etnograafiamuuseumiks. Nimemuutus oli mõneti põhjendatudki, sest seoses eesti rahvaluulele ja kultuuriloole pühendatud kirjandusmuuseumi eraldamisega ja kogude osalise ümbersuunamisega saigi kunagisest ERM-ist põhiliselt vaid etnograafiaga tegelev asutus.
} 
graafiainstituudi direktori Sergei Tolstovi suunava artikli „Etnograafia ja nüüdisaeg" avaldamine ERM-i aastaraamatus aastal $1947 .{ }^{13}$ Tolstovi artikkel tõlgiti nõukogude etnograafia juhtivast ajakirjast Sovetskaja etnografija (nr 1, 1946). Samas aastaraamatus avaldati ka Harri Moora artikkel, mis kohandas nõukogude etnograafia nõudmisi Eesti oludele. Moora järgi pidi etnograafia jätkuvalt keskenduma vana, kapitalismieelse talurahvakultuuri uurimisele, ent võtma varasemast enam arvesse esemete ja nähtuste sotsiaalset konteksti ning pöörama tähelepanu naaberrahvastele (Moora 1947).

Moora oli rahvuslikult meelestatud mees. Tema püüdeks oli, et rahvusliku identiteedi seisukohalt oluline etnograafia jääks püsima ka uutes oludes. Muuta polnudki tegelikult vaja kuigi palju, sest Eesti ja Nõukogude etnograafia ainevald kattus suuresti. Mõningaid järeleandmisi valitsevale ideoloogiale tuli loomulikult teha, aga need jäid suuresti vaid retooriliseks, nagu edaspidi näeme.

Märtsis aastal 1950 leidis Moskvas aset NSVL TA Etnograafia Instituudi korraldatud Baltimaade etnograafiale pühendatud konverents, millest võtsid osa ka Eesti teadlased. Ühiselt leiti, et uurida tuleb eeskätt tööliste ja talupoegade olme sotsialistlikku ümberkujundamist ning Baltimaade rahvaste etnogeneesi. $^{14}$ (Leete jt 2008: 23; Astel 2009: 224) Etnogenees oli üks tollase Nõukogude etnograafia peateemasid. Konverentsist kasvas välja koostöö Baltikumi ja Moskva etnograafide vahel, viimastel oli seejuures muidugi juhtiv ja suunav roll.

Aastatel 1952-1960 tegutses NSVL TA Etnograafia Instituudi Baltimaade ühendatud kompleksne ekspeditsioon. Uuriti sotsialistlikke ümberkorraldusi külas ning etnogeneesi. Viimane oli interdistsiplinaarne ettevõtmine, milles lisaks etnograafidele osalesid ka folkloristid, keeleteadlased, arheoloogid ja antropoloogid. ${ }^{15}$ Etnograafide rolliks oli detailselt uurida traditsioonilist rahvakultuuri, aitamaks välja selgitada rahvaste etnilist ajalugu ning kultuurisuhteid naaberrahvastega. Seoses sellega tuli jälgida ka rahvakultuuri territoriaalset liigendust. 1920.-1930. aastatel tehtud töö materiaalse kultuuri uurimisel kulus nüüd marjaks ära: vana hea ajaloolis-geograafilise meetodiga võis jätkata ka uutes oludes, tuli vaid lisada marksismi-leninismi klassikute tsitaate ja rõhutada vene rahva positiivset rolli Eesti ajaloos. Kaasaegsest lääne teadusest, mida Nõukogude Liidus demoniseeriti kui „kodanlikku", oli Eesti Stalini ajal ära lõigatud ning strukturalism, funktsionalism ja teised tollased moodsad suunad siia ei jõudnud. (Ränk 1978: 326-327; Leete jt 2008: 23)

Kompleksekspeditsiooniga seotud eestlaste liidriks oli Harri Moora. Moskva kolleegide toetus oli aidanud tal Eesti haritlaskonda tabanud kodanliku natsionalismi süüdistuste ajal suurematest repressioonidest pääseda ning ta säilitas oma positsiooni ENSV TA Ajaloo Instituudis. Tema toimetatud artiklite kogumik „Eesti rahva etnilisest ajaloost” (1956) oli tollase eest-

${ }^{13}$ Aastaraamat ilmus taas pärast pikemat vaheaega. Selle kaanel oli uuele algusele viitav number I, sulgudes oli aga ka järjepidevust tunnustavalt number XV.

${ }^{14}$ Termin etnogenees tuleb kreekakeelsetest sõnadest ethnos 'rahvas' ja genesis 'sünd, teke' ning tähendab hõimude ja rahvaste teket ja kujunemist.

${ }^{15}$ Nõukogude antropoloogid tegelesid füüsilise antropoloogiaga, mõõtsid kolpasid, määrasid silmade ja juuste värvi jne. Kultuuri- ja sotsiaalantropoloogiat Nõukogude Liidus ei olnud. 
laste etnogeneesi alase uurimistöö silmapaistvaim saavutus. See raamat viis eestlaste juured Eestis väga kaugesse minevikku ning rõhutas nende põlisust. Sealt sai alguse väide, et eestlaste otsesed eellased asusid tõenäoliselt Eesti alale juba 5000 aasta eest (kammkeraamika kultuur). Seda väidet populariseerisid hiljem teised, näiteks Lennart Meri. Kogumik tõlgiti kohe ka vene keelde $^{16}$ ning oli eeskujuks teistele samalaadsetele uurimustele Nõukogude Liidus. Tollase töö tulemuste hulka kuulub ka Harri Moora abikaasa Aliise Moora (1900-1996) monograafia „Peipsimaa etnilisest ajaloost” (1964).

1950. aastate teisel poolel, Hruštšovi „sula” päevil, toimus Eesti etnograafias rida positiivseid muutusi. Harri Moora vabanes põlu alt ja sai aastal 1957 ENSV TA akadeemikuks. Sama aasta jaanuaris leidis Tartus aset ENSV TA etnograafide nõupidamine. Järgnes ENSV TA Presiidiumi otsus kogumistöö arendamisest ERM-is. Selle sisuliseks autoriks oli ilmselt eeskätt Moora. Hävimisohus etnograafilist materjali tuli koguda nii Eestis kui ka naaberrahvaste juures. Olustiku ja tööprotsesside fikseerimiseks soovitati kasutada ka filmiülesvõtteid. Samuti tuli taaselustada muuseumi korrespondentide võrgu töö. Selle otsuse mõju vältas aastakümneid. (Konksi 2009: 251) Püstitatud ülesannete elluviimiseks määrati 1958. aasta suvel ERM-i direktoriks Aleksei Peterson (1931-2017), äsja ülikooli lõpetanud noor teotahteline etnograaf, kes püsis selles ametis kuni 1992. aastani. ${ }^{17}$ Petersoni eestkostjaks oli jällegi Harri Moora (Peterson, intervjuu 12. VIII 2016).

1959. aasta aprillis tähistati Tartus suurejooneliselt ERM-i 50. sünnipäeva. See tähendas järjepidevuse tunnustamist. Juubeli puhul ilmus üle pika aja taas muuseumi aastaraamat (nr XVI) ning toimus esinduslik teaduskonverents. Võib öelda, et juubeliga kaasnes ERM-i kui tõelise teadusasutuse maine taastamine (Luts 1999: 37). Teaduskonverentsidest sai iga-aastane traditsioon ja aastaraamat on sellest peale ilmunud regulaarselt. Kasutusele jäi vana, 1925. aastal alustatud numeratsioon.

Neil aastail sõlmiti taas sidemed Soome kolleegidega. Tartut külastasid Soome rahvateadlased Kustaa Vilkuna, Toivo Vuorela, Niilo Valonen jt. Neist visiitidest said alguse pikaajalised teaduskontaktid ja sõprussidemed. (Luts 1999: 13-14, 34; Konksi 2009: 270) Läbikäimine „kodanliku” Soomega oli seni välisilmast pea täiesti isoleeritud Eesti etnograafidele väga oluline, aidates levitada ideid ning turgutada enesekindlust.

Etnograafilise kogumistöö keskuseks Eestis oli jätkuvalt ERM. Lisaks tegeleti sellega 1957. aastal Tallinnas asutatud vabaõhumuuseumis (peamiselt ehitised) ja vähemal määral ka kohalikes muuseumides. Sõjajärgsel perioodil toimusid maaelus suured muudatused, eeskätt seoses põllumajanduse kollektiviseerimise ning kiire linnastumisega. Vana eesti rahvakultuur oli kadumas ja etnograafide ülesanne oli veel päästa, mis päästa annab. Nagu öeldud, ulatub see „päästeetnograafia” traditsioon tagasi XX sajandi algusse. Endiselt huvituti põhiliselt vanast, käibelt kadunust ja kaduvast. Aastatega muutus kogumistöö ERM-is mingis mõttes eesmärgiks omaette. Nõukogude

16 „Вопросы этнической истории эстонского народа” (Tallinn, 1956).

${ }^{17}$ Aleksei Peterson oli NLKP liige aastail 1957-1990. Samal ajal oli ta omajagu rahvuslikult mõtlev mees ja suhtus nõukogude võimu küllalt kriitiliselt, eriti oma ametiaja teisel poolel. 
süsteem armastas kasvavaid arvulisi näitajaid. ${ }^{18}$ 1961. aastal algas ERM-is rahvapäraste töövõtete ja -protsesside filmilindile jäädvustamine. Osa sellest materjalist monteeriti etnograafilisteks filmideks. Nõukogude etnograafia kontekstis oli see üsna tavatu (vt pikemalt Niglas, Toulouze 2010; Jääts 2011).

1960. aastate keskel asuti NSVL TA Etnograafiainstituudi koordineerimisel koostama Baltimaade ajaloolis-etnograafilist atlast („Историко-этнографический атлас Прибалтики"). See tähendas taas traditsioonilist esemeuurimist ja levikukaartide koostamist ning neelas suure osa Eesti etnograafide tööjõust kuni 1970. aastate lõpuni. Töö tulemusena ilmusid köited „Maaharimine” („Земледелие”, Vilnius 1985) ја „Rõivastus” („Одежда”, Riia 1986). Kolmas, küladele ja ehitistele pühendatud köide pidi ilmuma Eestis, kuid selle ettevalmistamine takerdus Läti ja Moskva etnograafide vastuolude tõttu ning see jäigi ilmumata (Leete jt 2008: 26). Etnograafiliste atlaste koostamisega tegeleti tollal ka mitmel pool mujal Euroopas.

Nõukogude Eesti etnograafia püsis üsna traditsioonilisena. Eesti etnograafide lemmikteemadeks jäid rahvarõivad, rahvakunst ja taluehitised. Ühelt poolt soodustasid seda Moskva etnograafide algatatud suured koostööprojektid, teisalt Eesti etnograafide endi valikud.

Rahvarõivad olid olulised eeskätt seoses eestlaste laulupeotraditsiooniga. Alates 1930. aastaist hakati laulupidudel kandma rahvarõivaid ning ERM-i etnograafid pidasid oluliseks, et vana rahvarõivast kasutataks võimalikult õigel, ajaloolisel kujul (Astel 2009: 238). Muuseumis leiduvad rahvarõivad olid selles kontekstis originaalid, autentsuse mõõdupuu, mille järgi tuli valmistada kaasajal kantavad koopiad. Rahvarõivanäitused ja temaatilised trükised olid populaarsed. ${ }^{19}$ Rahvarõivaste valmistamine ja kandmine andis inimestele võimaluse leida kontakti oma etniliste juurtega ning väljendada rahvuslikku identiteeti. Nõukogude ametlik kultuuripoliitika soosis rahvarõivaste kasutamist. Riiklikel pühadel ja muudel tähtpäevadel oli kombeks esile tõsta nõukogude rahvaste etnograafilist eripära, demonstreerida rahvuskultuuride õitsengut. (Kannike 1994: 8, 12, 15; Konksi 2009: 300-302) Stalin oli juba 1930. aastail kirjutanud, et nõukogude kultuur peab olema „vormilt rahvuslik, sisult sotsialistlik”. Rahvarõivad olid „rahvusliku vormi” osa ning nende uurimiseks oli seega olemas sotsiaalne tellimus nii ülalt kui ka alt.

Rahvakunst on üheks enim uuritud teemaks eesti etnograafias läbi aegade. Paljud õppeasutused ja tarbekunstnikud pidasid oluliseks jälgida oma töös vana rahvakunsti eeskujusid. (Astel 2009: 242) Ka rahvakunstiga, olgu või stiliseeritud kujul, said võimud väljendada ideed vormilt rahvuslikust, kuid sisult sotsialistlikust kultuurist, inimesed jällegi oma rahvuslikku identiteeti. Rahvakunsti ainetel valmistati palju suveniire. 1966. aastal asutati Tallinnas Rahvakunstimeistrite Koondis „Uku”, mis tootis nii kudumeid, kangaid kui ka õllekappasid, veimevakku ja sõlgi ning ammutas seejuures inspiratsiooni etnograafilisest vanavarast.

${ }^{18}$ Tollase kogumistöö kriitikat vt Pärdi 1991: 561-564; Konksi 2009: 290.

19 Olulisimad publikatsioonid sel teemal olid H. Moora toimetatud „Eesti rahvarõivaid XIX sajandist ja XX sajandi algult” (1957) ning Melanie Kaarma ja Aino Voolmaa „Eesti rahvarõivad" (1981). 
Taluehitistest oli etnograafide põhiliseks huviobjektiks rehielamu, mis oli levinud eeskätt Eestis, aga ka Põhja-Lätis. ${ }^{20}$ Ainulaadsest elamutüübist kujunes omalaadne rahvuslik sümbol. Seoses kolhoosikorra kindlustumise ja maaparandustöödega muutusid Eesti kultuurmaastikud 1960. aastail kiiresti ning ühes sellega hakkasid rehielamud kaduma. Rehielamute lammutamist maaelu sotsialistliku ümberkorraldamise käigus ei tajunud paljud eestlased aga lihtsalt ühe ajale jalgu jäänud elamutüübi teisega asendamisena, vaid veel ühe valusa hoobina rahvusliku pärandi pihta. Alaliselt rehielamuis elada ehk enam ei tahetud, sest puudusid mugavused, suvekoduks sobisid need aga suurepäraselt. Vabaõhumuuseumi üheks esimeseks hooneks oli klassikaline Sassi-Jaani talu rehielamu Lääne-Eestist. Kui see 1984. aastal segastel asjaoludel maha põles, levis eestlaste seas kumu, et süütamise taga seisavad eestlusse vaenulikult suhtuvad jõud. Talu taastati ja avati uuesti aastal 1993.

Lisaks tegeleti muidugi ka teiste traditsioonilise rahvakultuuri tahkudega: uuriti põllutööriistu ja maaharimist, käsitööd, transporti, toitu ja muud. Rahvakultuuri vaimset poolt uuris folkloristika, mis nõukogude süsteemis oli seotud keele- ja kirjandusteadusega. Folkloristid tegelesid ka selliste etnograafia ja folkloristika piirimaile jäävate teemadega nagu pulmakombestik, rahvakalender ja uskumused. Viimasega ei tahtnud Eesti teadlased eriti tegeleda: tulemused pidid kaasa aitama ateistlikule võitlusele, ent sellesse ei soovitud panustada.

Kaasaja uurimine Eesti etnograafidel hästi ei õnnestunud, sest see oli seotud ideoloogilise tellimusega: tulemused pidid toetama riiklikku poliitikat. 1950. aastatel ette võetud katsed kolhoosielu uurida jooksid täielikult liiva, sest reaalsus ei vastanud üldse ametlikele ootustele. 1960. aastate esimesel poolel prooviti Võru rajoonis uuesti, taustaks NLKP XXII kongressi (1961) otsused maa ja linna vaheliste erinevuste kaotamisest. Resultaadiks oli rida artikleid ERM-i aastaraamatus (nr XXI, 1966). Hiljem tehti kaasaja uurimiseks veel välitöid Viljandi rajoonis ja Paide rajoonis Aravetel. Lisaks tavapärasele etnograafilisele lähenemisele kasutati sotsioloogilisi meetodeid, kuid avaldatud tulemused jäid napiks. (Leete jt 2008: 27; Konksi 2009: 311-326; 2004) Lihtsam, ausam ja meeldivam oli piirduda traditsioonilise talurahvakultuuriga, mis pealegi seostus eesti identiteediga ja toetas seda.

Etnograafia traditsioonilise ainevalla teatav avardumine nõukogude perioodil siiski toimus, osaliselt võib-olla Soome kolleegide eeskujul. Uuriti näiteks linnade töölisklassi eluolu ning eesti rahvakultuuri muutusi seoses XIX sajandi teisel poolel alanud moderniseerumise, industrialiseerumise ja urbaniseerumisega.

Ainsa nõukogude ajal ilmunud eesti etnograafia üldkäsitluse koostas Harri Moora ja Ants Viirese juhitud TA etnograafide töörühm. Venekeelne artikkel „Eestlased” ilmus raamatu „NSV Liidu Euroopa-osa rahvad” („Народы европейской части СССР”) teises köites (Moskva 1964). Pikem saksakeelne variant „Abriss der estnischen Volkskunde” valmis samal aastal. Eestikeelset üldkäsitlust Eesti etnograafiast nõukogude perioodil ei ilmunudki.

${ }^{20}$ Väljapaistvaimad nõukogudeaegsed publikatsioonid taluehitistest olid Karl Tihase „Eesti talurahvaarhitektuur” (1974) ja Tamara Habichti „Rahvapärane arhitektuur” (1977). 
Pärast Teist maailmasõda kadus eestlasi varem idapoolsetest soomeugrilastest eraldanud riigipiir ning 1960. aastate algul taaselustus Eestis soome-ugri etnograafia. Selle keskuseks kujunes ERM eesotsas Aleksei Petersoniga. Hakatuseks liituti Paul Ariste juhitud Tartu ülikooli keeleteadlaste ekspeditsioonidega, hiljem jätkati juba iseseisvalt. Alustati idapoolsete läänemeresoomlaste uurimisest. Esmalt toimus see Eesti etnilise ajaloo ja etniliste kontaktide uurimise kontekstis, avardudes pärast iseseisvaks uurimissuunaks. Huvituti eeskätt materiaalsest kultuurist ja tehti innukalt kogumistööd. Mõnel suvel korraldati lausa mitu soome-ugri ekspeditsiooni. Kokku laekusid nõukogude perioodil ERM-i kogudesse umbes 150 soome-ugri aladel tehtud välitöö materjalid (vt Auasi 2008).

Alates 1965. aastast osalesid Eesti etnograafid rahvusvahelistel fennougristika kongressidel. Kolmas kongress toimus 1970. aastal Tallinnas ja sellel oli innustav mõju. Ilmusid artiklite kogumikud „Läänemeresoomlaste rahvakultuurist” (1970) ja „Läänemeresoomlaste etnokultuuri küsimusi” (1982), toimetajaks Jüri Linnus. Neis rõhutati muuseas Eesti soome-ugri etnograafia järjepidevust ning tsiteeriti Ilmari Mannineni, mis Stalini ajal olnuks mõeldamatu.

Soome-ugri etnograafiliste esemete, eeskätt rahvakunsti vastu tunti huvi ka ENSV Riiklikus Kunstiinstituudis. Alates 1978. aastast korraldas kõrgkool Kaljo Põllu eestvõttel, sageli koostöös ERM-iga, iga-aastaseid ekspeditsioone soome-ugri ja samojeedi rahvaste juurde.

Huvi soome-ugri rahvaste vastu ei piirdunud keeleteadlaste, etnograafide ja folkloristidega. See puudutas ka paljusid loovharitlasi ja suurt osa eesti rahvast. Soomeugrilike seoste rõhutamine oli üks võimalusi väljendada oma nõukogude võimust sõltumatut eesti identiteeti. 1970. aastail võrsus fennougristikast terve kultuurisuund, mille näiteks on Lennart Meri etnograafilised dokfilmid, Veljo Tormise koorimuusika ja Kaljo Põllu graafika. (Eesti ajalugu 2005: 345-350)

Läbi raudse eesriide tungis ka Baltimaile 1960. aastate lõpul läänemaailmas toimunud kultuuriparadigma muutus: osa noorest linnaharitlaskonnast hakkas huvituma oma juurtest ning väärtustama nende ürgsust, vana rahvakultuuri hakati enda jaoks taasavastama ning ümbermõtestama, tekkis võimudest suhteliselt sõltumatu folklooriliikumine (vt Kuutma 2008: 590). Selle tuules kasvas ka etnograafilise vanavara populaarsus.

Nõukogude Eesti etnograafia sündis nõukogude režiimi ja sellega paralleelselt eksisteerinud ning pigem rahvuslikult meelestatud Eesti kodanikuühiskonna vahelises pingeväljas. Etnograafia funktsioon nõukogude võimu ja Eesti kodanikuühiskonna jaoks oli ilmselt erinev ja ajas muutuv. Stalini ajal võttis nõukogude võim etnograafiat üsna tõsiselt ning allutas selle energiliselt oma ideoloogilisele kontrollile. Hiljem võimu haare lõdvenes ning Eesti etnograafia libises tagasi oma vanasse rahvusteaduse sängi, teenides pigem Eesti kodanikuühiskonda kui nõukogude võimu.

Kui varem oli nõukogude võim lootnud Eesti etnograafiat enda huvides ära kasutada, siis alates 1960. aastaist seda pigem umbusaldati. Näiteks ei ehitatud ERM-ile uut hoonet ja pidurdati vabaõhumuuseumi arengut (eriti 
1980. aastail). ${ }^{21}$ Tundub, et neid asutusi ei peetud oluliseks või peeti koguni „kahtlasteks”. Kui Stalini ajal eeldati, et kultuur muutub tasapisi sotsialistlikuks ka vormilt, siis nõukogude perioodi lõpukümnendeil kippus ta pigem muutuma rahvuslikuks ka sisult. Etnograafia ajalugu Nõukogude Eestis oli osa sellest muutusest.

\section{Etnoloogia taasiseseisvunud Eestis}

Eesti taasiseseisvus 1991. aasta augustis. Marksism-leninism kui etnograafia teoreetiline alus heideti kõrvale. Sagenesid kontaktid välismaiste kolleegidega, eeskätt Soome ja Rootsi etnoloogidega ning Eesti etnograafia joondus lääne eeskujude järgi nii teooriate, meetodite kui ka teemade valikul. Teaduse nimetusena võeti nüüd kasutusele etnoloogia. ${ }^{22}$ Kui nõukogude perioodil oli etnograafia kõrvuti teiste rahvusteadustega teataval määral toiminud kultuurilise vastupanu kanalina, siis taasiseseisvunud Eestis vajadus selleks kadus. Rahvusluse roll ühiskonnas teisenes ning ühtlasi muutus ka rahvusluse ja etnoloogia suhe. Kui varasem etnograafia oli rahvuse ehitamisel kaasa töötanud, siis uus etnoloogia kujunes pikapeale pigem rahvusluse kriitikuks ja dekonstrueerijaks. Oma mõju oli läänemaailmas 1980. aastail hoo sisse saanud ja 1990. aastatel jõudsalt jätkunud rahvusluse uuringutel, mis olid seni enesestmõistetava ja seega peaaegu nähtamatu rahvusluse järk-järgult osadeks lahti võtnud ja „paljastanud”, vähemalt osa haritlaste silmis.

Nõukogude Eestis oli Tartu ülikool ainus paik, kus sai etnograafiks õppida. 1990. aastail loodi seal taas etnoloogia professuur. Esimeseks korraliseks professoriks oli Elle Vunder. Hiljem hakati lisaks Tartu Ülikoolile etnoloogiat ning kultuuriantropoloogiat õpetama ka Tallinna Ülikoolis ja mõningal määral Eesti Kunstiakadeemias, ent etnoloogiat, kultuuri- ja sotsiaalantropoloogiat võis nüüd õppima suunduda Euroopa ja Ameerika ülikoolidessegi. Kõik see tõi kaasa Eesti etnoloogide (ja antropoloogide) ringi laienemise ja mitmekesistumise.

Varasemaga võrreldes avardusid hüppeliselt publitseerimisvõimalused. Teaduse rahastamise süsteem muutus põhjalikult. Kui nõukogude perioodil rahastati uurimistööd riiklike teadusasutuste eelarvest, siis alates 1990. aastatest toimub see projektipõhiselt: uurijatel tuleb oma töö finantseerimiseks konkureerida mitmesuguste kodu- ja välismaiste fondide rahale ning see on kindlasti mõjutanud teemade valikut ja käsitlusviisi.

Võib-olla reaktsioonina varasemale etnograafiale, mis keskendus suuresti materiaalse kultuuri kirjeldavale ja võrdlevale uurimisele ning eelistas suunata pilgu minevikku, on taasiseseisvunud Eesti etnoloogid püüelnud laiema kultuurikäsitluse poole, huvitunud pigem vaimsest kultuurist ja tegelenud ka

${ }^{21}$ Samal ajal kasutati vabaõhumuuseumi tollase teadusdirektori Elle Vunderi (snd 1939, ametis 1971-1988) sõnul omamoodi paraadmuuseumina, kuhu viidi Nõukogude Eesti võimuladviku tähtsaid külalisi (Vunder, intervjuu 24. IX 2017).

${ }^{22}$ Nimemuutusega taheti end ühelt poolt otsustavalt distantseerida nõukogude etnograafiast. Teisalt tähistati lääne teaduskirjanduses terminiga etnograafia pigem meetodit, mingi rahva või kultuurinähtuse kirjeldust kui iseseisvat teadusdistsipliini ning see tekitanuks segadust. Etnograafia nimetati tollal etnoloogiaks ümber ka Venemaal. 
kaasajaga. Lihtsustatult ja utreeritult võib öelda, et asjade asemel on Eesti etnoloogia fookusesse nihkunud inimene kui kultuurikandja ja -looja. Tunda on Skandinaavia kultuurianalüüsi, kultuurisemiootika, rahvusluse uuringute ja lääne antropoloogias toimunud refleksiivse pöörde ${ }^{23}$ mõjusid.

Materiaalse kultuuri uurimine on jätkunud vähesel määral ja uuenenud kujul ning omandanud rakendusliku kallaku. Vanade käsitöötehnikate vastu tuntakse küll üsna laialdast, ent mitte tingimata akadeemilist huvi.

Eesti etnograafide-etnoloogide senise Eesti-teemalise töö kokkuvõttena on ilmunud mahukas ja soliidne üldkäsitlus „Eesti rahvakultuur” (1998; teine, täiendatud trükk 2008).

\section{Kokkuvõtteks}

Eesti etnograafia on algusest peale olnud tihedalt seotud rahvuslusega nii selle laiemas kui ka kitsamas tähenduses. XIX sajandi teisel poolel tekkinud rahvusliku liikumise raames hakati väärtustama traditsioonilist rahvakultuuri ning selle elemente kasutati ehituskividena moodsa eesti rahvuse ehitamisel. Eesti etnograafia peamiseks uurimisobjektiks oli kuni 1990. aastateni talurahvakultuuri materiaalne osa, samal ajal kui folkloristika tegeles selle vaimsema poolega. Sõdadevahelises Eesti Vabariigis oli etnograafia üks rahvusteadusi ning aitas omalt poolt kaasa rahvusliku identiteedi tugevdamisele. Nõukogude perioodil oli Eesti etnograafia formaalselt osa Nõukogude etnograafiast ja allutatud marksistlik-leninistlikule teooriale, ent tegelikult toimis see alates 1950. aastate lõpust suuresti edasi rahvusteadusena, jäädes oma uurimisainese ja -meetodite osas kaunis konservatiivseks. Suur muutus leidis aset 1990. aastatel. Eesti etnograafia sulas nüüd ühte Euroopa etnoloogiaga ning vastavalt muutus ka distsipliini nimetus. Teooriate ja meetodite osas joonduti kaasaegsete Euroopa eeskujude järgi ning uurimisvaldkond laienes oluliselt. Rahvusluse roll Eesti ühiskonnas on muutunud. Teisenenud on ka rahvusluse ja etnoloogia suhe. Lühidalt öeldes on etnograafiast kui kunagisest rahvuslusele kaasaaitajast saanud selle kriitiline kõrvaltvaataja.

\section{Intervjuud}

Peterson, Aleksei. Intervjuu 12. VIII 2016. Intervjueerijad Indrek Jääts, Piret Õunapuu.

Vunder, Elle. Intervjuu 24. XI 2017. Intervjueerija Marleen Metslaid.

\section{Kirjandus}

Astel, Eevi 2009. Eesti Rahva Muuseum aastatel 1940-1957. - Eesti Rahva

Muuseumi 100 aastat. Koost Piret Õunapuu. Tartu: Eesti Rahva Muuseum, lk $186-247$.

${ }^{23}$ Refleksiivseks pöördeks nimetatakse 1960.-1970. aastatel antropoloogide uurimustest alguse saanud paradigmamuutust sotsiaal- ja humanitaarteadustes: uurija peab teadvustama oma isiku mõju uurimistööle, oma akadeemilise tegevuse laiemat konteksti. 
Auasi 2008 = Auasi. Eesti etnoloogide jälgedes. A matter of honour. In the footsteps of Estonian ethnologists. Дело чести. По следам эстонских этнологов. Koost Svetlana Karm, Marleen Nõmmela, Piret Koosa. Tartu: Eesti Rahva Muuseum.

B en d ix, Regina 1999. Time and ourselves: The discomforts of reflexive disciplinary history: Response to Wolfgang Kaschuba. - Journal of Folklore Research, kd 36, nr 2-3, lk 179-183.

Eesti ajalugu 2005 = Jüri Ant, Mart Laar, Kaido Jaanson, Mart Nutt, Raimo Raag, Sulev Vahtre, Andres Kasekamp, Eesti ajalugu, VI. Vabadussõjast taasiseseisvumiseni. Peatoim S. Vahtre. Tartu: Ilmamaa.

Garberding, Petra 2011. Swedish ethnologists and folklorists and Nazi race politics. - Current Issues in European Cultural Studies; June 15-17; Norrköping; Sweden 2011. (Linköping Electronic Conference Proceedings 62.) Linköping: Linköping University Electronic Press, lk 293-301. http://www.ep.liu. se/ecp/062/ecp11062.pdf (3. I 2018).

Gellner, Ernest 1994-1995. Rahvused ja rahvuslus. Tlk Anneli Andresson. Akadeemia 1994, nr 10, lk 2207-2238; nr 11, lk 2429-2462; nr 12, lk 2653-2686; Akadeemia 1995, nr 1, lk 197-222; nr 2, lk 419-446; nr 3, lk 643-670.

Greenfeld, Liah 2001. Etymology, definitions, types. - Encyclopedia of Nationalism, kd 1. Fundamental Themes. San Diego, California-London: Academic Press, lk 251-265.

Jääts, Indrek 2005. Etnilised protsessid Vene impeeriumi siseperifeerias 1801-1904. Komi rahvusluse sünd. (Dissertationes Ethnologiae Universitatis Tartuensis 2.) Tartu: Tartu Ülikooli Kirjastus.

Jääts, Indrek 2011. Tagasivaade etnograafilise filmi sünniloole Eesti Rahva Muuseumis. Aleksei Petersoni 80. sünnipäeva puhul. - Kaks filmi eesti etnograafiast. Aleksei Peterson 80. (Eesti etnograafiline film 1.) Eesti Rahva Muuseum. (DVD juurde kuuluv brošüür.)

Kannike, Anu 1994. „Rahvuslik” rahvakultuur. - Pro Ethnologia, nr 2. Etnoloogia ja muuseumid. Tartu: Eesti Rahva Muuseum, lk 7-16.

Kle in, Barbro 2006. Cultural heritage, the Swedish folklife sphere, and the others. - Cultural Analysis, nr 5, lk 57-80.

Ko n ksi, Karin 2004. Arved Luts ja Nõukogude Eesti kaasaja dokumenteerimine Eesti Rahva Muuseumis. - Eesti Rahva Muuseumi aastaraamat XLVIII. Tartu: Eesti Rahva Muuseum, lk 13-46.

Konksi, Karin 2009. Etnograafiamuuseumina Nõukogude Eestis 1957-1991. Eesti Rahva Muuseumi 100 aastat. Koost Piret Õnapuu. Tartu: Eesti Rahva Muuseum, lk 250-355.

Ku u t m a, Kristin 2008. Rahvakultuurisajand omakultuurist folklooriliikumiseni. - Eesti rahvakultuur. Koost, toim Ants Viires, Elle Vunder. Tallinn: Eesti Entsüklopeediakirjastus, lk 586-598.

Leete, Art, Tedre, Ülo, Valk, Ülo, Viires, Ants 2008. Uurimislugu. - Eesti rahvakultuur. Koost, toim A. Viires, Elle Vunder. Tallinn: Eesti Entsüklopeediakirjastus, lk 15-39.

Luts, Arved 1999. Teel juubelile. Tagasivaade Eesti Rahva Muuseumi 50. aastapäevale ja selle eelloole. - Eesti Rahva Muuseumi aastaraamat XLIII. Tartu: Eesti Rahva Muuseum, lk 11-40.

Lö fgre n, Orvar 1989. The nationalization of culture. - Ethnologia Europaea, kd 19, lk 5-23. 
Lö fg r e n, Orvar 1990. The danger of knowing what you are looking for. On routinizing research. - Ethnologia Scandinavica, kd 20, lk 3-15.

Mannin en, Ilmari 1924. Etnograafia tegevuspiiridest ja sihtidest Eestis. - Eesti Kirjandus, nr 12, lk 527-537.

Metslaid, Marleen 2016. Between the Folk and Scholarship: Ethnological Practice in Estonia in the 1920s and 1930s. (Dissertationes Ethnologiae Universtitatis Tartuensis 5.) Tartu: University of Tartu Press.

M o o r a, Harri 1947. Eesti etnograafia nõukogulikul ülesehitamisel. - Eesti Rahva Muuseumi aastaraamat I (XV). Tartu: Teaduslik Kirjandus, lk 24-35.

Nic Craith, Máiréad 2008. From national to transnational: A discipline en route to Europe. - Everyday Culture in Europe. Approaches and Methodologies. (Progress in European Ethnology.) Toim M. Nic Craith, Ullrich Kockel, Reinhard Johler. Aldershot-Burlington: Ashgate, lk 1-17.

Niglas, Liivo, Toulouze, Eva 2010. Reconstructing the past and the present: The ethnographic films made by the Estonian National Museum (1961-1989). Journal of Ethnology and Folkloristics, kd 4, nr 2, lk 77-96.

Niir a n e n, Timo 1992. Pioneers of Finnish ethnology. - Pioneers. The History of Finnish Ethnology. (Studia Fennica Ethnologica 1.) Toim Matti Räsänen. Helsinki: Suomalaisen Kirjallisuuden Seura, lk 21-40.

Nõ m mela, Marleen 2010. The state, the museum and the ethnographer in constructing national heritage: Defining Estonian national costumes in the 1930s. - JEF. Journal of Ethnology and Folkloristics, kd 4, nr 1, lk 49-61.

Pärdi, Heiki 1991. Kriitilise pilguga Eesti Rahva Muuseumi esemekogumise poliitikast. - Keel ja Kirjandus, nr 9, lk 561-566.

Rihtman-Auguštin, Dunja 2004. Ethnology, Myth and Politics. Anthropologizing Croatian Ethnology. (Progress in European Ethnology.) Toim Jasna Čapo Žmegač. Aldershot-Burlington: Ashgate.

Roga n, Bjarne 2014. Popular culture and international cooperation in the 1930s. CIAP and the League of Nations. - Networking the International System. Global Histories of International Organizations. Toim Madeleine Herren. Springer International Publishing, lk 175-185.

Ränk, Gustav 1935. Päevaküsimusi eesti rahvusteaduste töömailt. - Üliõpilasleht, nr 5, 7. IV, lk 178-181.

Ränk, Gustav 1937. Etnograafilise uurimistöö praegune seisukord ja tuleviku kavatsused selle arendamiseks. - ERK: Üld-, Majandus- ja Kultuuripoliitiline ajakiri, nr 5-6, lk 115-122.

Ränk, Gustav 1978. Ethnographic studies. - A Case Study of a Soviet Republic: The Estonian SSR. Toim Tönu Parming, Elmar Järvesoo. Boulder, Colorado: Westview Press, lk 319-339.

Slezkine, Yuri 1994. The USSR as a communal apartment, or how a socialist state promoted ethnic particularism. - Slavic Review, kd 53, nr 2, lk 414-452.

T alv e, Ilmar 1992. Ilmari Manninen in Finland and Estonia. - Pioneers. The History of Finnish Ethnology. (Studia Fennica Ethnologica 1.) Toim Matti Räsänen. Helsinki: Suomalaisen Kirjallisuuden Seura, lk 50-76.

V alk, Ülo 2004. On the discursive foundations of Estonian folkloristics: A farmer's field of vision. - Everyday Life and Cultural Patterns. International Festschrift for Elle Vunder. (Studies in Folk Culture 3.) Toim Ene Kõresaar, Art Leete. Tartu: Tartu University Press, lk 265-272. 
Vi ires, Ants 1998. Eesti pagulasetnograafid Rootsis. - Keel ja Kirjandus, nr 10, lk 691-703.

Viires, Ants 2000. Rahvusteadused ja rahvateadus. - Teaduslik konverents rahvakultuuri terminoloogiast. Toim Ants Salum. Viljandi: Viljandi Kultuurikolledž, lk 5-11.

Özkırımlı, Umut 2000. Theories of Nationalism. A Critical Introduction. Palgrave.

\section{Estonian ethnography and Estonian nationalism}

Keywords: ethnography, ethnology, nationalism, history of science, Estonian National Museum

The article analyses the relations between Estonian ethnography and Estonian nationalism ever since the discipline was born until the present day.

Although Estonians had already been of ethnographic interest to some BalticGerman and Russian intellectuals since the late $18^{\text {th }}$ century, Estonian ethnography proper, which has always been mainly concentrated on the material aspect of Estonian folk culture, was not born until the turn of the $20^{\text {th }}$ century, hand in hand with Estonian nationalism. As Estonians belonged to the so-called peoples without history, the intellectuals who started to build a modern Estonian nation did not have much to go on but the traditional peasant culture. Thus, in the framework of the nationalist discourse, that culture acquired a new positive meaning and some of its elements came to be valued as a foundation of the national culture under construction. The traditional peasant culture became essential for the Estonian national identity, due to which ethnography became a science supporting it.

In the 1920s and 1930s, when Estonia was a sovereign nation, ethnography was one of the national sciences contributing to the enhancement of Estonian national identity and the people's sense of unity. In the Soviet period, Estonian ethnography was part of Soviet ethnography and as such it was expected to follow its MarxistLeninist theory. In fact, since the late 1950 s it was largely practised as a national science, which was rather conservative both in research material and method.

A big change took place in the 1990s. Estonian ethnography merged with European ethnology. This was a different discipline addressing a considerably wider range of research problems. A change in the role of nationalism in the Estonian society brought along a change in the relation between nationalism and ethnology. In short, ethnography, which once used to be a contributor to Estonian nationbuilding, has become ethnology, a critical observer of nationalism.

Indrek Jääts (b. 1971), PhD, Estonian National Museum, Researcher, ijaats@gmail.com

Marleen Metslaid (b. 1982), PhD, Estonian National Museum, Researcher, marleen.metslaid@erm.ee 